\title{
Failure Rates and Data Driven Policies for Vehicle Safety Inspections in Pennsylvania
}

\author{
Dana Peck $^{\text {a,b,*, H. Scott Matthews }}{ }^{\text {a,b,1, }}$, Paul Fischbeck ${ }^{\text {b,c,2, }}$, Chris T. \\ Hendrickson ${ }^{\text {a,3 }}$
}

${ }^{a}$ Department of Civil and Environmental Engineering, Carnegie Mellon University, 5000 Forbes Avenue, Pittsburgh, PA 15213, USA

${ }^{\mathrm{b}}$ Department of Engineering and Public Policy, Carnegie Mellon University, 5000 Forbes Avenue, Pittsburgh, PA 15213, USA

${ }^{\mathrm{c}}$ Department of Social and Decision Sciences, Carnegie Mellon University, 5000 Forbes Avenue, Pittsburgh, PA 15213, USA

* Corresponding author. Tel.: +1 413262 8856, E-mail address: danapeck@cmu.edu

${ }^{1}$ Tel.: +1 412268 7813, E-mail address: hsm@ @ cmu.edu

${ }^{2}$ Tel.: +1 412268 3240, E-mail address: pf12@andrew.cmu.edu

${ }^{3}$ Tel.: +1412268 1066, E-mail address: cth@cmu.edu 


\section{INTRODUCTION}

In the United States, mass transportation vehicles such as public transit, commercial flight, and passenger rail are federally mandated to undergo safety and maintenance inspections. However, the federal government does not require inspections of personal vehicles even though it is the most pervasive travel mode according to passenger-miles traveled [1]. Without a federal mandate, states determine the extent and frequency of light duty vehicle (LDV) safety inspections. As of January 2014, thirteen states require annual safety inspections (some of which also require emission inspections), a handful of states require safety inspections at change of vehicle ownership, about half of states require only emissions inspections, and ten states require neither [2].

Safety programs call for specified inspections to be performed on automobiles and light trucks with varying frequencies (e.g., annually) and on various subsets of the fleet (e.g., exempting new cars). These state safety inspection requirements change over time, largely due to the general perception that such programs are costly to consumers and provide little or no benefits to society. Behind these perceptions are perceptions that cars have never been safer. States are also considering eliminating safety inspections entirely as government reports indicate the vast majority of vehicles successfully pass the inspection requirements. Pennsylvania is one of those states.

Legislators in Pennsylvania have claimed (without literature attribution) that $98 \%$ of inspected vehicles pass inspection [3], implying a $2 \%$ failure rate. Stakeholders in other states have made similar statements, thus implying that the failure rate is so low that it presents an unnecessary burden on drivers or that there is no evidence it is an effective program. ${ }^{1,2}$ With lack of substantial evidence, these other states have recently discontinued their safety inspection programs. However, during the inspection process, vehicles may provisionally fail, receive repairs, and then be classified as "pass." The intermediate repairs or adjustments, which are likely lost amongst the data from where the low failure rates are drawn, should have been

\footnotetext{
${ }^{1}$ According to a Washington Post article, "D.C. officials said that only about 20 states have inspection programs and that there is no evidence that routine inspections make District vehicles less accident-prone." [4]

${ }^{2}$ According to New Jersey news, "the [safety] inspections resulted in a rejection rate of less than 6 percent for "serious" defects — such as those related to brakes, steering or suspension, state officials said." [5]
} 
classified as failures under the current inspection regime. Determining failure rates before and after maintenance is essential to assessing and improving safety inspection programs. To account for this, in this study vehicles recorded as "work performed to pass" are considered to have failed. This modification will yield an improved failure rate estimate. More importantly, this updated failure rate assesses the direct effect of the program by identifying vehicle owners who rely on vehicle safety inspections to identify safety problems and maintain their vehicle. For instance, drivers who proactively maintain their vehicle(s) are assumed to fix problems as they occur and therefore would not be represented in this improved failure rate estimate methodology. Using this assumption, it is possible this fail rate estimate may be an underestimate of actual vehicle fail rates. However, conclusions cannot be drawn here because these analyses can only be performed by observing multi-point data inspections or by comparing the condition of vehicles in non-inspection states; however, there is no available data to reflect this.

This study uses two unique datasets containing anonymized vehicle safety inspection records for the state of Pennsylvania to examine the actual failure rate of inspected vehicles, and projected failure rates of various data-driven inspection scenarios. In addition to overall failure rates, we examine failure rates by vehicle mileage, vehicle age, urbanity, and failure rate trends over time. In addition, the question of whether accurate inspection data is available and correctly analyzed is addressed. Finally, conclusions are drawn on the changes in vehicle safety, the importance of continued vehicle maintenance, various policy perspectives on the implementation of the current program, and whether the current safety inspection program seems to be worthwhile to continue in the future at this point.

\section{VEHICLE SAFETY HISTORY AND LITERATURE REVIEW}

Due to an unfortunately high rate of traffic fatalities in the mid-1900s, the Highway Safety Act of 1966 was enacted [6]. Until 1973, the states were federally required to have safety inspection programs in order to qualify for federal highway funds with the notion that these inspections, along with roadway improvements (hence the federal highway fund), would reduce traffic fatalities. Previous studies of safety inspection programs have been high-level analyses of whether states without safety inspection programs have higher crash or fatality rates, which provides at best, indirect measures of effectiveness. In recent publications, there have been numerous approaches to improve vehicle safety on the road. 
These recent publications include, but are not limited to modeling safety-related driving behavior, the effectiveness of safety-based incentives, crash analysis, and road safety forecasting. In 2005, Bonsall, et al. identified key parameters of traffic simulation models to project real, unsafe behavior of drivers instead of ideal, safe behavior of drivers to help improve the safety of driving conditions. [7] Noland and Quddus examined whether time periods with congestion versus without congestion influenced factors affecting number of fatalities resulting from vehicle crashes. [8] Abdel-Aty et al., in 2013, investigated whether it is informative and worthwhile to use macro-level modeling of vehicle crashes, by using Geographic Information System (GIS), to help inform policy and decision makers of safety investments. [9] In 2013, Weijermars and Wesemann used road safety forecasting and ex-ante evaluation in policy making in the Netherlands to achieve road safety targets and reduce fatalities and serious road injuries. [10] Vehicle safety inspections, however, haven't been studied extensively as a tool even though they may help in both reducing fatal crashes and keeping roads safe, by requiring vehicle owners to actively maintain the condition of vehicle components.

Historically, both cross-sectional and time-series analyses of vehicle safety inspections have been performed; yet, the majority are now outdated. Vehicle technologies have rapidly changed, and analyses from 30 years ago are not comparable to today's vehicle travel and inspection analyses. However, methods can be observed and applied on the present vehicle data, with current travel patterns and vehicle inspection results. Overall, these past studies have varying conclusions as to whether or not vehicle safety inspection programs are effective.

In 1980, Crain compared death and crash rates, through an economic analysis, in states with and without inspection programs, using 1974 cross-sectional data [11]. In states with inspection programs, a benefit-cost analysis concluded that random safety inspections were as effective as the periodic inspections in preventing crashes and deaths; and, the periodic inspection program thus should be either reevaluated or terminated, as they are more costly than periodic inspections, yet have the same effect as the periodic inspections. In 1984, Loeb et al. published a time-series analysis of the efficacy of the inspection program in reducing fatalities, injuries, and crashes using data from the state of New Jersey. A benefit cost-analysis proved the inspection program to be cost-effective and significantly reduced the number of highway fatalities [12]. Even just looking at these two studies, it can be seen that a state-specific analysis yields different results from the high-level countrywide analysis comparing states with and 
without inspection programs. The safety inspection program is in need of a state-focused analysis rather than a general nation-wide analysis.

Loeb created an econometric model for efficacy of inspection in reducing fatalities and injuries using cross-sectional data from 1979. He used his previous work from New Jersey as a reference state to compare to the other states across the country. Loeb concluded that there was significant evidence of the efficacy of motor vehicle safety inspections in reducing motor vehicle related crashes and mortalities [13]. Garbacz and Kelly (1987) implemented a national timeseries analysis to analyze mandated vehicle safety inspections impact on fatalities. An ordinary least squares regression was presented, using fatalities from the National Safety Council (19521982) and then adjusted for traffic fatalities. The results showed no evidence that safety inspection reduced fatalities. A benefit-cost analysis was performed and found that the vehicle safety inspections had no benefits, and were not cost-effective. [14] In light of these conflicting results, the safety inspection program is in need of a state-focused analysis rather than a general nation-wide analysis.

In 1994, Leigh found that vehicle safety inspection laws were not found to significantly reduce fatalities per capita. Leigh compared the quantity of inspections required and the effects of those inspections on fatalities per capita. [15] Merrell et al. (1999) also found no evidence that inspections significantly reduce fatality or injury rates. The state-level model in this analysis was based on the frequency of inspections; the resulting variables were used in an econometric equation along with both fatal and non-fatal estimated models. [16] Rather than comparing fatal and non-fatal models, a more concrete analysis would be to first distinguish a base case of fatalities and how these fatality counts change due to the inspection frequency changes. In 2002, Poitras and Sutter analyzed inspection effectiveness by observing the presence of older vehicles on the road and the impact on the repair industry. Their results indicated that inspections had no significant impact on old cars or the repair industry. [17] This study did not identify how or if the inspection program with older vehicles was compared to the program for the entire vehicle fleet. Additionally, Sutter and Poitras (2002) examined political motives for inspections and produced a model between the incidence of inspection across states and inspection fees. They concluded the inspection program existed primarily due to political transaction costs. [18]

Ages of vehicles are not widely considered in any of the noted previous literature, yet likely have importance in designing an appropriate policy or tax for inspection programs. Two 
travel trends may have effects on safety inspection results. First, previous studies show older vehicles being driven less and second, the total vehicle miles traveled has been flat or decreasing since 2004 according to the Federal Highway Administration [19].

Two state-level studies exist for the states of Pennsylvania and North Carolina. In 2007, the Pennsylvania Department of Transportation (PennDOT) hired Cambridge Systematics to study its safety inspection program [20]. Pennsylvania is considered to be one of the most rigorous safety inspection programs implemented in the country. In their analysis, four years of data on fatalities were examined at both the state and county-level to assess the effectiveness of the vehicle safety program. They used various national databases (e.g., NHTSA's Fatality Analysis Reporting System, U.S. Census, National Oceanic and Atmospheric Administration, etc.) to account for weather, demographics, and socioeconomic variables. The Cambridge study estimated 1 to 2 fewer fatalities per billion vehicle miles traveled (VMT) for any state with a safety program and concluded that the vehicle safety inspection program was effective. The Cambridge study specifically recommended development and use of the electronic state safety inspection ("e-SAFETY") program. A contradicting 2008 study, sponsored by North Carolina legislators, found that "no evidence exists showing the safety program is effective" and "program oversight by DMV is inadequate". The study referenced the use of crash data from Nebraska's Division of Motor Vehicles comparing the three-year crash average before and after the discontinuation of Nebraska's vehicle safety inspection program. While they do not find the inspection to effectively reduce vehicle component fatal crashes, they state a limitation to the analysis is that "because law enforcement personnel are not mechanics and receive a minimal amount of training in compiling and reporting accident data, it is unlikely a true assessment of how many accidents result from mechanical defects is possible". [21] Additionally, they use a safety inspection dataset consisting of about six million records over only one year (2007) and claim the study is not in-depth enough to be extrapolated to the entire country. Furthermore, those certified by the DMV to oversee the inspection stations and audit them yearly were reported to have spent less than three percent of their time on this activity. The report admitted that the quality and uniformity of inspections is difficult to enforce, especially in a decentralized inspection program such as North Carolina's.

This overview of previous literature shows that the majority of vehicle safety inspection publications are relatively old and showed mixed conclusions on whether or not safety inspection 
programs were effective. Furthermore, these analyses were mostly high-level, comparing overall state inspection program effectiveness and generally not using detailed, county-level, inspection record datasets. It is valuable to do a more detailed analysis due to the varying implementation of the safety inspections from state to state and varying driving patterns from vehicle to vehicle. This may show that a state with stronger oversight and rigorousness may prove to be a more effective program overall. As shown in the following discussion, within the state of Pennsylvania, vehicle ages, locations, and total miles traveled vary and the need for state-specific analyses is necessary. Additionally, no paper was found to explicitly analyze actual safety inspection pass or fail rates, which may greatly aid an effectiveness study on the inspection level rather than fatal crash level. The remainder of this paper assesses the vehicle safety inspection program in the state of Pennsylvania on a detailed level addressing failure rates by urban/rural county types, vehicle age, and overall vehicle odometer reading.

\section{THE PA STATE VEHICLE INSPECTION PROGRAM, PROCESS, AND DATA RECORDS}

In Pennsylvania, safety inspections of LDVs are administered annually in every county and for all vehicles. Inspection stations in Pennsylvania are an open market; if an individual or business decides to perform inspections in Pennsylvania, they apply to PennDOT. Upon verification that they meet the requirements and have cleared screening at PennDOT they are appointed as a certified safety inspection station. The number of safety inspection stations depends on the number of stations that have been certified. In order for individuals to perform safety inspections, they must be trained and certified by PennDOT. Inspectors are compensated by the business for which they work, as per the business' individual practices. Both the inspection stations and inspectors receive periodic oversight audits and are monitored by the State Police Vehicle Fraud Unit. Any violations, such as lost stickers, improper use of license, or affixing stickers incorrectly, are subject to possible suspension and fines. The cost of a vehicle inspection is market-set, where each inspection station chooses how much it will charge. In most cases, vehicle owners are charged an inspection fee in addition to any maintenance performed; however, some businesses may choose to offer annual inspections free of charge. PennDOT charges inspection stations or inspectors approximately two dollars per inspection sticker (which 
is used to distinguish a vehicle has been inspected). A vehicle with an expired inspection sticker in the state of Pennsylvania is subject to various fines. Additional detailed information on the Pennsylvania vehicle inspection program can be found in The Pennsylvania Code 67 Pa. Code $\S$ 175. [22]

Vehicle safety inspection regulations and processes are uniform across Pennsylvania yet vary between states. For example, one state may check brakes via a "skid" test, measuring the distance to stop from a given speed and pressing the brakes. Another state may physically measure the thickness of the brake pads. This could create an inconsistency in inspection results state to state since the different inspection methods are not correlated against each other, and thus are likely to give different safety outcomes. Some Pennsylvania counties (25 of 67) also require emissions inspections, generally around urbanized areas whose air quality does not meet federal standards as stated in the Clean Air Act (1990). This paper focuses solely on safety inspections as pertaining to LDV's in Pennsylvania.

Initially, certified inspection stations in Pennsylvania were required by the state to document all inspection results using a paper MV-431 form (refer to the Supplemental Material). Historically, these detailed but typically hand-written inspection records were subject to periodic station audits to assure proper recordkeeping. This form of decentralized record keeping prevents data analytics from being performed and is most likely why there have been so few studies on this topic.

Vehicle safety inspections in Pennsylvania include checking vehicle components such as: steering/suspension, exhaust, fuel, body/doors/latches, glazing/mirrors, brake system, lighting, tires, and other. The "other" category includes all or some of the following categories: wipers, bumper, defrosters, battery hold-down, brake warning lights, odometer, speedometer, etc. To pass the safety inspection, the state of the vehicle after inspection, with or without maintenance, must be within the applicable, allowable thresholds. For example, the minimum threshold for tire tread depth is $2 / 32$ inch. The result of each required component check is coded as a pass, fail, new, repair, or adjust. Figure 1 explains the various paths that can be taken during the safety inspection process, starting with the initial inspection that identifies potential component problems. 


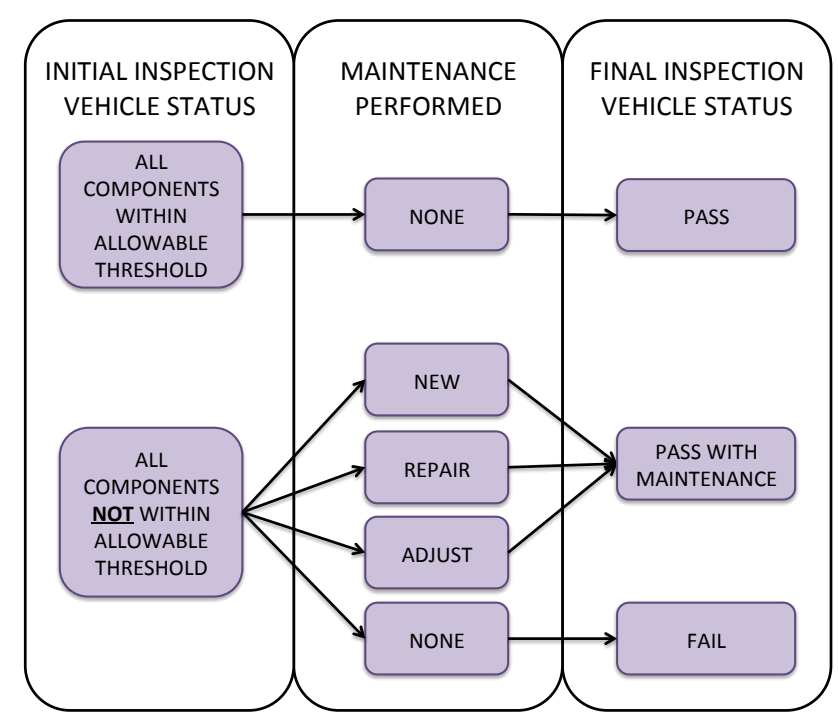

Figure 1: Representation of Inspection Process

Table 1 presents examples of component inspection problems identified with a corresponding maintenance solution, along with the reason for the type of failure, or the "work performed" at the inspection station.

Table 1: Definition of Action Categories with Example Solutions

\begin{tabular}{cll}
\hline Action & \multicolumn{1}{c}{ Scenario } & \multicolumn{1}{c}{ "Work Performed" } \\
\hline New & $\begin{array}{l}\text { A vehicle's tire tread is measured as less } \\
\text { than threshold tired depth }\end{array}$ & $\begin{array}{l}\text { Tire is replaced, a new tire } \\
\text { is installed }\end{array}$ \\
Repair & $\begin{array}{l}\text { The hood latch is broken or is not } \\
\text { keeping the hood locked down }\end{array}$ & $\begin{array}{l}\text { The latch is repaired so it } \\
\text { functions properly }\end{array}$ \\
Adjust & Headlights are mis-aimed & $\begin{array}{l}\text { Headlights are re-aimed, or } \\
\text { adjusted }\end{array}$ \\
\hline
\end{tabular}

If all tested components are initially within the allowable threshold, then the final inspection status is considered a pass; and no maintenance was required to receive the inspection sticker. The pass with maintenance designation represents a vehicle with one or more components identified during the initial inspection as requiring maintenance because they were not within the allowable threshold. Once all suggested maintenance is performed and all components are within the allowable threshold, the vehicle passes and receives an inspection 
sticker. The fail designation represents a vehicle with one or more components identified during the initial inspection as requiring maintenance because they are outside of the allowable threshold, yet not all required repairs were performed. This vehicle will not leave the inspection with a new safety inspection sticker. For example, the vehicle owner may be told work is necessary for the vehicle to pass; however, the suggested work may not always be performed at that time and the owner may return at a later date. Identifying failure rates based only on results of final inspection status ignores the fact that maintenance is often required, and may lead to false perceptions of failure.

The fail, new, repair, and adjust categories, combined, all represent ways in which a vehicle would have failed an inspection if maintenance was not performed and reflect a vehicle's initial state when entering the inspection station, regardless of the final status. This is important to consider when estimating the safety effects in a regime without an inspection program, as these adjustments or replacements may have never otherwise happened without the required safety inspection program. Since vehicles must have valid safety inspection permits to be driven, owners request the inspection facility to make the necessary repairs and adjustments to the vehicle so that all components eventually receive a new safety inspection sticker. Thus, the majority of vehicles are considered to have successfully passed inspection. Examining the underlying information about maintenance during an inspection is thus necessary.

In Pennsylvania, inspection data is recorded and held in databases owned by PennDOT as well as by privately owned IT contractors and inspection companies. Full inspection data records are considered proprietary, and are not generally used for program performance assessment.

Five years ago, PennDOT launched the "e-SAFETY" program, an electronic data archive of safety inspection results, where safety inspection stations voluntarily report results of vehicle inspections. The impetus of this program was to ensure collection of data to distinguish "trends for future safety improvements by identifying potential vehicle safety hazards and safety patterns". [23] When the e-SAFETY program was introduced, part of the incentive to participate was that the MV-431 paper forms were no longer necessary for record documentation. Some stations still may choose to keep them as the primary inspection record.

Prior to the commencement of the e-SAFETY program, a private company, CompuSpections, LLC (CompuSpections), released commercial software to manage and monitor 
vehicle safety inspections on behalf of stations, such as those required by states like Pennsylvania. Rather than inspections being voluntarily submitted, the private company is able to collect all of the data entered into the software system. The initial incentive for this private electronic system was to be used for a managerial device and was not necessarily intended to use to report these safety inspection results. The CompuSpections database offers the option to print MV-431 forms from the entered information.

Both the CompuSpections and e-SAFETY datasets have comparable data, but differ by the details for variables they contain (see Methodology section). Both the e-SAFETY and CompuSpections databases allow inspection stations to have quick and detailed access to previous records when necessary. This may be important in order to back-check any repairs made to a vehicle involved in a crash or to monitor reported failures to be sure they are not overreported. Additionally, this program allowed vehicles to be tracked according to any type of changes made for a "failing" vehicle in order to prevent or look for similar failures in same model-year vehicles. The key difference between the two datasets lies in composition of types of inspection stations. The majority of the e-SAFETY data records are comprised from independent inspection stations, while records in the CompuSpections database are mainly from dealership inspection locations. Additionally, e-SAFETY records have higher odometer readings, on average, given a specific vehicle age. By combining these inspection datasets, these data samples are assumed to be representative of safety inspection failure rates in the entire state.

By combining inspection details from both datasets and comparing various distributions with state registration data distributions, we can examine how many vehicles have safety issues and are repaired as a result of the current annual safety inspection program. With this information, various analyses can be performed based on vehicle inspection failure rates or number of vehicles that "would have failed" with respect to the characteristics such as urban/rural county types, vehicle age, and overall vehicle odometer reading. 


\section{METHODOLOGY FOR FILTERING, VALIDATING, AND ANALYZING STATE VEHICLE RECORDS TO CALCULATE INSPECTION FAILURE}

\section{RATES}

In calculating vehicle safety inspection failure rates, this study focuses on three main parameters by which failure rate is analyzed. These parameters consist of vehicle failure rate by urban/rural county classification, age, and odometer reading. Age is an essential variable by which to calculate failure rates because driving patterns differ as a result of vehicle age, with VMT decreasing about three percent per year, on average. Furthermore, there are fewer older (more than ten years old) vehicles being driven [24]. This however does not mean the old vehicles should be ignored from analyses since they still contribute to fatal crashes. An additional reason to consider fail rate by age is because PA state legislators have proposed to exempt safety inspections based on a vehicle's age (e.g., exempt first two years of safety inspections). A county-scheme distribution allows for conclusions to be drawn based on the population density of a given location, allowing for assertions to be made depending on varying

driving patterns due to driving location (e.g., rural county vehicles are driven more yet represent less of the state). Finally, failure rates are examined based on odometer readings, which perhaps reflect both vehicle age and driving location, as younger vehicles tend to be driven more than older vehicles and vehicles in rural counties tend to be driven more than those in urban counties. The following sections present the data available for this analysis, validation and regression of the data, as well as each of the previously stated failure rate distribution scenarios.

\subsection{Raw Data}

Raw data provided for this study includes anonymized Pennsylvania vehicle safety inspections ranging from 2008-2012 from two different data sources, in addition to anonymized Pennsylvania vehicle registration records as of March 2012 and November 2013. The two datasets are composed of varying volumes of records, vehicle characteristics, and inspection information. No information pertaining to the vehicle owner or drivers of the vehicle was identified or released. Table 2 summarizes the main similarities and differences pertinent to the study. 
Table 2: Pennsylvania Data Used

\begin{tabular}{|c|c|c|c|}
\hline & e-SAFETY & CompuSpections & Registration \\
\hline Record Count & 980k (total) & 3.3 million (total) & 10.4 million (each) \\
\hline Frequency & $\begin{array}{c}5 \text { years } \\
(2008-2012)\end{array}$ & $\begin{array}{c}5 \text { years } \\
(2008-2012)\end{array}$ & $\begin{array}{c}2 \text { snapshots } \\
\text { (March '12 \& November '13) }\end{array}$ \\
\hline $\begin{array}{l}\text { Percent of Registered } \\
\text { Vehicles per Year }\end{array}$ & $\sim 3 \%$ & $\sim 10 \%$ & \\
\hline VIN & $\mathrm{X}$ & $\mathrm{X}$ & $\mathrm{X}$ \\
\hline Odometer & $\mathrm{X}$ & $\mathrm{X}$ & $\mathrm{X}^{*}$ \\
\hline Date & $\mathrm{X}$ & $\mathrm{X}$ & $\mathrm{X}^{*}$ \\
\hline $\begin{array}{l}\text { Location } \\
\text { (zip code) }\end{array}$ & $\mathrm{X}$ & $\mathrm{X}$ & $\mathrm{X}^{*}$ \\
\hline $\begin{array}{l}\text { Vehicle make and/or } \\
\text { model }\end{array}$ & $\mathrm{X}$ & $\mathrm{X}$ & \\
\hline $\begin{array}{l}\text { Inspection Type } \\
\text { (e.g. annual) }\end{array}$ & $\mathrm{X}$ & $\mathrm{X}$ & \\
\hline $\begin{array}{l}\text { Inspection Action } \\
\text { (e.g. pass, new, etc.) }\end{array}$ & $\mathrm{X}$ & $\mathrm{X}$ & \\
\hline
\end{tabular}

*At time of registration for current owner in PA

Custom code written in the Python programming language was used to filter, analyze and compare each initial, raw dataset to remove entries with invalid or incomplete information.

Filters used on each dataset included, but were not limited to, the following primary issues:

1) Invalid VIN (length, digits, verified)

2) Duplicate Entries

3) Invalid Date (format issue - not a date, no entry)

4) Invalid Odometer Entry (alpha-numeric entry, no entry)

5) Heavy-duty trucks ( $>10,000 \mathrm{lbs}$ and $\geq$ Ford F-350)

6) Permanently registered vehicles (police cars and ambulances)

7) Low category counts ( $<1,000$ vehicles in a given category i.e., age 25 vehicles)

The Supplemental Material (Section 2.2 Raw Data Filtering Results) contains detailed filtering and methodology information. About $10 \%$ of the registration data, about $2 \%$ of the CompuSpections data, and about $8 \%$ of the e-SAFETY data were removed from the initial datasets leaving sufficient, complete, and valid entries to complete the analyses. 
Registration data reported in the data sets was used to assess the representativeness of the vehicles in each data set since one of the mandatory steps in the inspection process is to verify registration. Thus the registration data is considered to be a valid baseline of vehicle representation for the analysis. Representativeness was examined between each registration dataset as well as between registration and inspection datasets. While chi-squared analyses suggest that the distributions compared are statistically different (see Section 3 in the Supplemental Material), the distributions do appear to follow the same trends and overall distribution appearance. However, there are specific reasons as to why only certain years were included in the data analysis, specifically pertaining to the quantity of records in each inspection dataset contributing to the overall, combined inspection dataset.

A limitation to the two inspection databases is that they are not randomly selected records of vehicles overall in the state or of types of stations (e.g. independent or dealership). And, while the inspection datasets provide an ample amount of inspection data points, it is concluded the statistical difference merely indicates the vehicle fleet is rapidly changing with many new cars moving onto the market, old cars off of the market, and cars moving into and out of the state. Another problem in checking for statistically similar data distributions may stem from vehicles

being registered in Pennsylvania and getting inspected in a station that does not partake in the electronic state inspection program, but rather in a station that still uses the paper MV-431. Finally, it is concluded that the total number of data points (refer to Table 2) is enough to be able to draw reasonable conclusions about the vehicle fleet, even if it is not statistically proven.

\subsection{Data Validation and Regression Analysis}

In order to determine if any independent variables of vehicle characteristics are statistically significant in predicting the dependent variable of vehicle safety inspection outcome (whether a vehicle will pass or fail inspection), a logistic regression is performed using the statistical software package $\mathrm{R}$. The outcome in this equation is treated as a Bernoulli trial and the following logistic function is used:

$$
p(x)=\frac{1}{1+e^{-\eta(x)}}
$$

- where $\mathrm{p}(\mathrm{x})$ is the probability of the outcome $\mathrm{x}$ (i.e., $\mathrm{p}$ (failing inspection)); 
- and $\eta(x)$ is a linear combination of explanatory variables:

$$
\begin{array}{r}
\eta(x)=\beta_{o}+\beta_{1} * \text { age }+\beta_{2} * \text { currentOdometer }+\beta_{3} * \text { weight }+\beta_{4} * \text { fuelEconomy }+ \\
\beta_{5} * \text { InspectDate }+\beta_{6} * \text { urbanity }+\beta_{7} * \text { body }+\beta_{8} * \text { make }+\beta_{9} * \text { fuelType }
\end{array}
$$

- where age, currentOdometer, weight, fuelEconomy, InspectDate, urbanity (of registration location), are continuous variables;

- and body, make, fuel are binary variables;

To test for multicollinearity, we have calculated and provided a correlation matrix showing variable relationships. Note that the regression model incorporates urbanity index as a categorical variable, but for the sake of looking at the correlation between variables, the urbanity level was assumed to be continuous based on the urbanity scale explained in the following section of the paper. The correlation matrix of the independent, continuous variables are shown in Table 3.

Table 3: Correlation Matrix of Independent, Continuous Variables Included in the Logistic Regression

\begin{tabular}{lcccccc}
\hline & $\begin{array}{c}\text { Vehicle } \\
\text { Age }\end{array}$ & $\begin{array}{c}\text { Current } \\
\text { Odometer }\end{array}$ & $\begin{array}{c}\text { Vehicle } \\
\text { Weight }\end{array}$ & $\begin{array}{c}\text { Fuel } \\
\text { Economy }\end{array}$ & $\begin{array}{c}\text { Urbanity } \\
\text { Level }\end{array}$ & $\begin{array}{c}\text { Inspection } \\
\text { Date }\end{array}$ \\
\hline Vehicle Age & 1 & 0.79 & -0.13 & -0.05 & 0.08 & 0.19 \\
Current Odometer & & 1 & -0.06 & -0.05 & 0.11 & 0.16 \\
Vehicle Weight & & & 1 & -0.78 & 0.03 & 0.04 \\
Fuel Economy & & & & 1 & -0.04 & -0.03 \\
Urbanity Level & & & & & 1 & 0 \\
Inspection Date & & & & & & 1 \\
\hline
\end{tabular}

These correlation results show that, as would be expected, odometer and age are correlated at about 0.8 , as well as fuel economy and weight, which are correlated at about -0.8 .

After observing two pairs of variables in the logistic regression with high correlation values, we are careful to observe the standard error values of the coefficients in the logistic regression results. These results are summarized in Table 4. 
Table 4: Summary of Continuous Variable Estimates from Logistic Regression

\begin{tabular}{lcccc}
\hline \multicolumn{1}{c}{ Variables } & Coefficient & Standard Error & z value & $\operatorname{Pr}(>|\mathbf{z}|)$ \\
\hline (Intercept) & -31 & 1.9 & $-1.7 \mathrm{E}+01$ & $<2 \mathrm{e}-16 * * *$ \\
Vehicle Age & $5.7 \mathrm{E}-02$ & $4.9 \mathrm{E}-04$ & $1.2 \mathrm{E}+02$ & $<2 \mathrm{e}-16 * * *$ \\
Current Odometer & $1.2 \mathrm{E}-05$ & $4.4 \mathrm{E}-08$ & $2.6 \mathrm{E}+02$ & $<2 \mathrm{e}-16 * * *$ \\
Vehicle Weight & $9.4 \mathrm{E}-05$ & $4.1 \mathrm{E}-06$ & $2.3 \mathrm{E}+01$ & $<2 \mathrm{e}-16 * * *$ \\
Fuel Economy & $2.1 \mathrm{E}-02$ & $6.5 \mathrm{E}-04$ & $3.2 \mathrm{E}+01$ & $<2 \mathrm{e}-16 * * *$ \\
Inspection Date & $1.3 \mathrm{E}-06$ & $9.2 \mathrm{E}-08$ & $1.4 \mathrm{E}+01$ & $<2 \mathrm{e}-16 * * *$ \\
\hline$* * *$ highly significant & \multicolumn{5}{|}{}
\end{tabular}

According to Menard (2001), high multicollinearity increases standard errors, yet coefficients remain unbiased. As observed in Table 4, standard errors are small enough that we can conclude multicollinearity is not a concern and that it does not affect our coefficient estimates, since they are significant even when including all variables [25]. All coefficients in the regression were found to be highly significant, as shown by the very small probabilities in Table 4. In effect, the dataset is sufficiently large and varied to allow good estimation of effects such as age versus odometer reading. In order to further prove that multicollinearity should not be a concern, model checking and fit measures of models excluding the various combinations of correlated variables, in addition to the base case including all variables shown above, is presented in the Supplemental Material (Section 3.1 Logistic Regression).

After noting that all variables in the regression are significant, any of them can be used to make policy decisions for the vehicle safety inspection program. As a result, in following section, various failure rate scenarios are considered based on those that would be easiest to implement policy-wise.

\subsection{Vehicle Failure Rate Definition and Analysis}

We calculate failure rates for the different fail categories and then an overall failure rate for the state. As described in Section 3, the possible results of an initial inspection include: pass, fail, new, repair, and adjust. The final failure rate, considering only fail final inspection status, is calculated to be less than 0.1 percent. This rate is an order of magnitude lower than the implied $2 \%$ fail rate as stated by opponents of safety inspections. It must be noted that while this $<0.1 \%$ failure rate is very low, it may be an underestimate of the actual "fail" designation. This underestimate may result from lack of thorough recordkeeping. Vehicles that fail inspection may 
leave and return for maintenance at a later date, but because recordkeeping is only done once results are final (typically when a sticker is issued), this initial failed inspection may not be recorded. As previously explained, the vehicle owner may be told work is necessary for the vehicle to pass; however, the work may not always be performed at the time of the inspection. It is possible, since no sticker was issued, that there was no concern to record and/or report this inspection, solely for recordkeeping. This final failure rate alone, however, would not be indicative of the percent of unsafe cars on the road if the safety inspection program did not exist nor is it representative of the lack of compliance to the inspection law. A failure in this context should include the pass with maintenance final inspection status, which considers entries with any fail, new, repair, or adjust designations recorded in both the e-SAFETY and CompuSpections datasets. In this data model, a pass or fail (including pass with maintenance) was recorded as a '0' or ' 1 ', respectively. Multiple entries in a year may occur if a vehicle gets an inspection, fails, and no work is performed immediately. This inspection is recorded as a fail. Soon after, the vehicle may return to get re-inspected and pass inspection and thus a pass is recorded for the same vehicle. In this case, the first entry for the VIN is used as this is considered the initial safety inspection result. On the other hand, if this initial failed inspection is not recorded, as it would only be for record-keeping, and there is only record of the vehicle passing after it returns, this may result in an overestimate (underestimate) of the pass rate (failure rate). While this is important to note as an observation in the data, it was concluded that these entries were minimal compared to the quantity of data in total (see Supplemental Material Table 2), and therefore was not assumed to have an effect on the overall failure rate estimates.

The first analysis was to consider the "overall" LDV fail rate for the state as a whole by including pass with maintenance results. After filtering the registration database for the Pennsylvania state fleet, we are able to analyze about nine million LDVs of the 10.4 million registered vehicles. There were two methods used for calculating the overall state failure rate. First, the registration and inspection data was disaggregated by age, since this was the most detailed, common variable between datasets. Due to varying composition breakdowns by age between the inspection and registration data sets, we evaluate overall state failure rate by two different methods (see Supplemental Material Figure 4). Initially, using the failure rate by age combined with the vehicle distribution in the registration dataset, the overall state failure rate range was calculated to be about $18 \%$. Then similarly using the failure rate by age, but instead 
using the inspection vehicle distribution, the overall state failure rate was calculated to be about $12 \%$. These two values are both used in describing the failure rate for the state as being a range from $12 \%$ to $18 \%$. Using the average overall vehicle failure rate range and the registration total of about 10.4 million LDVs, equates approximately 1.3 to 1.9 million vehicles that would have failed inspection, in a given year. This metric clarifies the number of vehicles that would have otherwise failed inspections, without corrective action taken across the various state-mandated safety tests, which are currently implemented. Comparing this $12 \%$ to $18 \%$ failure rate back to the initial statement of the failure rate being only $2 \%$, equates to a difference in vehicles that would have failed inspection in a given year totaling between one and two million. This calculated failure rate range is one to two orders of magnitude higher than the failure rate claimed by state legislators. This large difference must not be ignored and creates a concern since there is suggestion to modify or eliminate the vehicle safety inspection program in the near future. These overall state failure rates of 12 - 18\% can be defined on a finer level by examining the vehicle failure rates by age, odometer reading, and county classification. In addition to these three listed characteristics, safety inspection failure rates by vehicle body can be found in the Supplemental Material (see Supplemental Material Figure 7).

Figure 2 displays the average vehicle inspection failure rate with respect to vehicle age, as well as the overall state failure rate for comparison. 


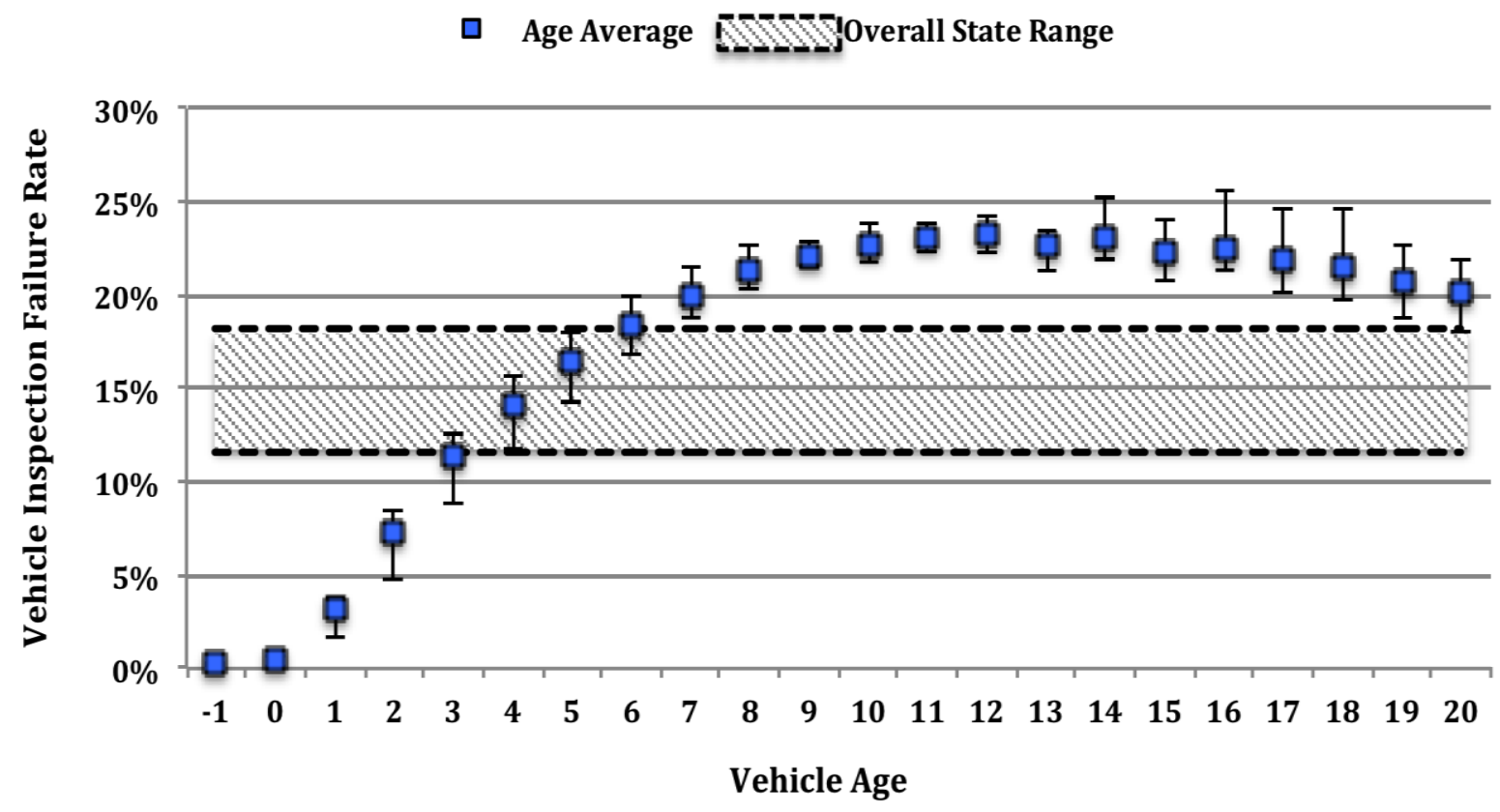

Figure 2: Failure Rates by Vehicle Age (error bars represent min-max failure rate range from 2008-2012). Age notation is calculated based on the model year and the more recent inspection year of the vehicles, so that the lowest age results in '-1' (e.g., a 2008 model-year vehicle could be purchased and inspected in 2007). Shaded range is the overall average failure rate for all vehicles during this time period.

Figure 2 shows a very low (but not zero) failure rate for new vehicles; vehicles aged -1 and 0 have average failure rates of $0.2 \%$ and $0.5 \%$, respectively and a failure rate of $3.2 \%$ beginning at age one. Even with one year of driving, the failure rate is already above the promoted $2 \%$ failure rate. Unlike the decreasing age distribution across the registered vehicles, the failure rate across the state increases with age and remains significant with older vehicles. Vehicles over eight years old consistently show a failure rate at or above $20 \%$, with the maximum failure rate of about $23 \%$ for vehicles around age 16 . Careful consideration must be taken into account when describing the overall state vehicle fleet since there is a large frequency of young vehicles with lower failure rates, compared to the older vehicles with much higher failure rates (see Supplemental Material Figure 4). It is also interesting to note that older cars fail less often than mid-range cars, perhaps due to less frequent driving trends in older vehicles, as mentioned previously. Furthermore, it is assumed people driving older cars are generally better at 
maintaining them or proactively making repairs themselves and therefore cause this decreased failure rate.

A more comprehensive presentation of the data would be to calculate how many vehicles "would have failed" without the current program. According to this standpoint, by eliminating the safety program, in 2012 on the order of 1.4 to 1.7 million failed vehicles would have been on the road in that year. Figure 3 combines the calculated failure rates from each inspection database with the number of vehicles from the registration database in order to represent the estimated number of vehicles that "would have failed" in the state in a given year.

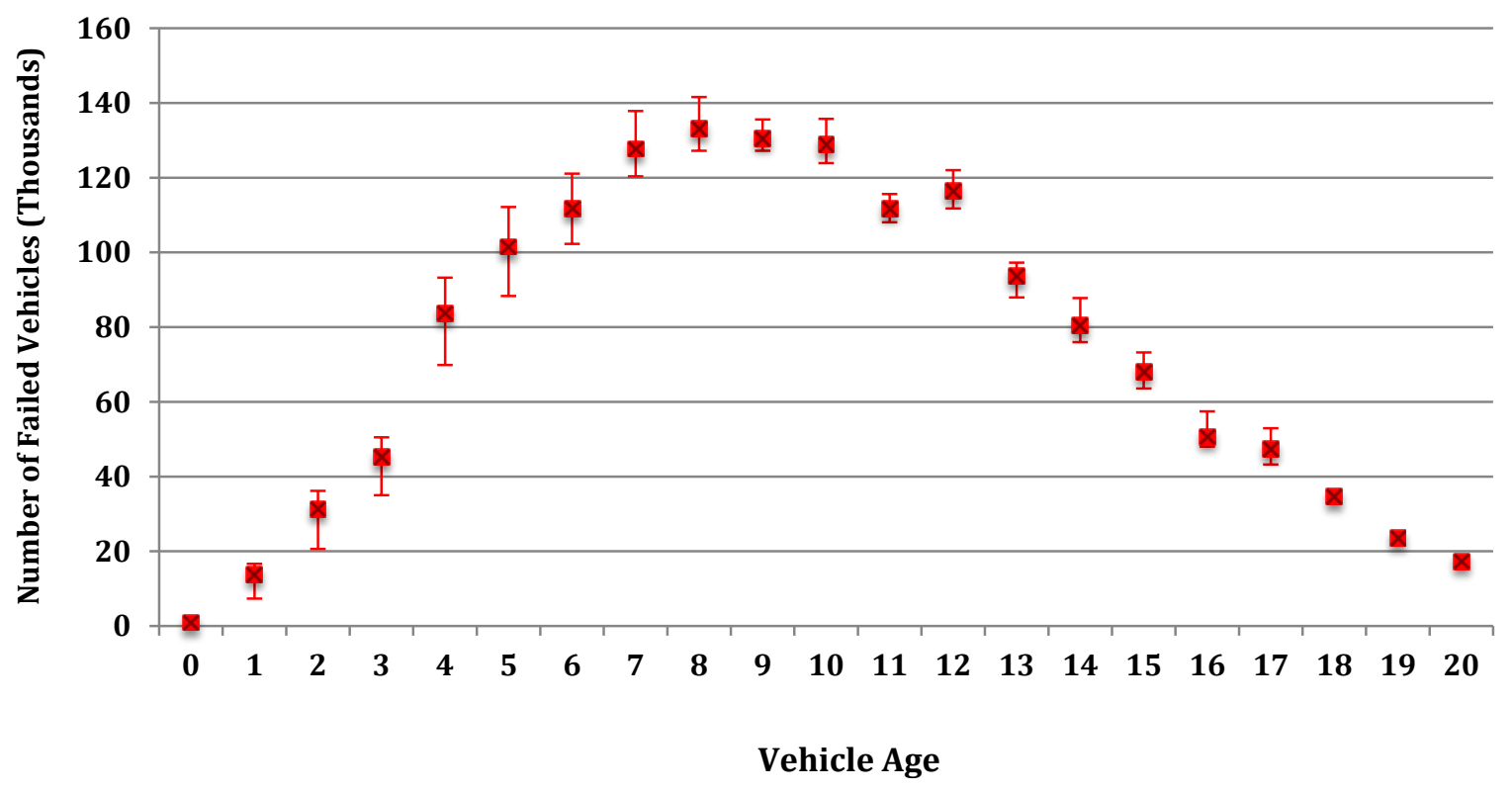

Figure 3: Estimated number of vehicles that would have failed in 2012, by vehicle age (bars represent range between $2008-2012$

The mid-aged vehicles generate the majority of "would have failed" vehicles. Estimates of the number of vehicles that would have failed by county can be found in the Supplemental Material Figure 5.

Next, the fail rate was examined by odometer reading and is displayed in Figure 4. 


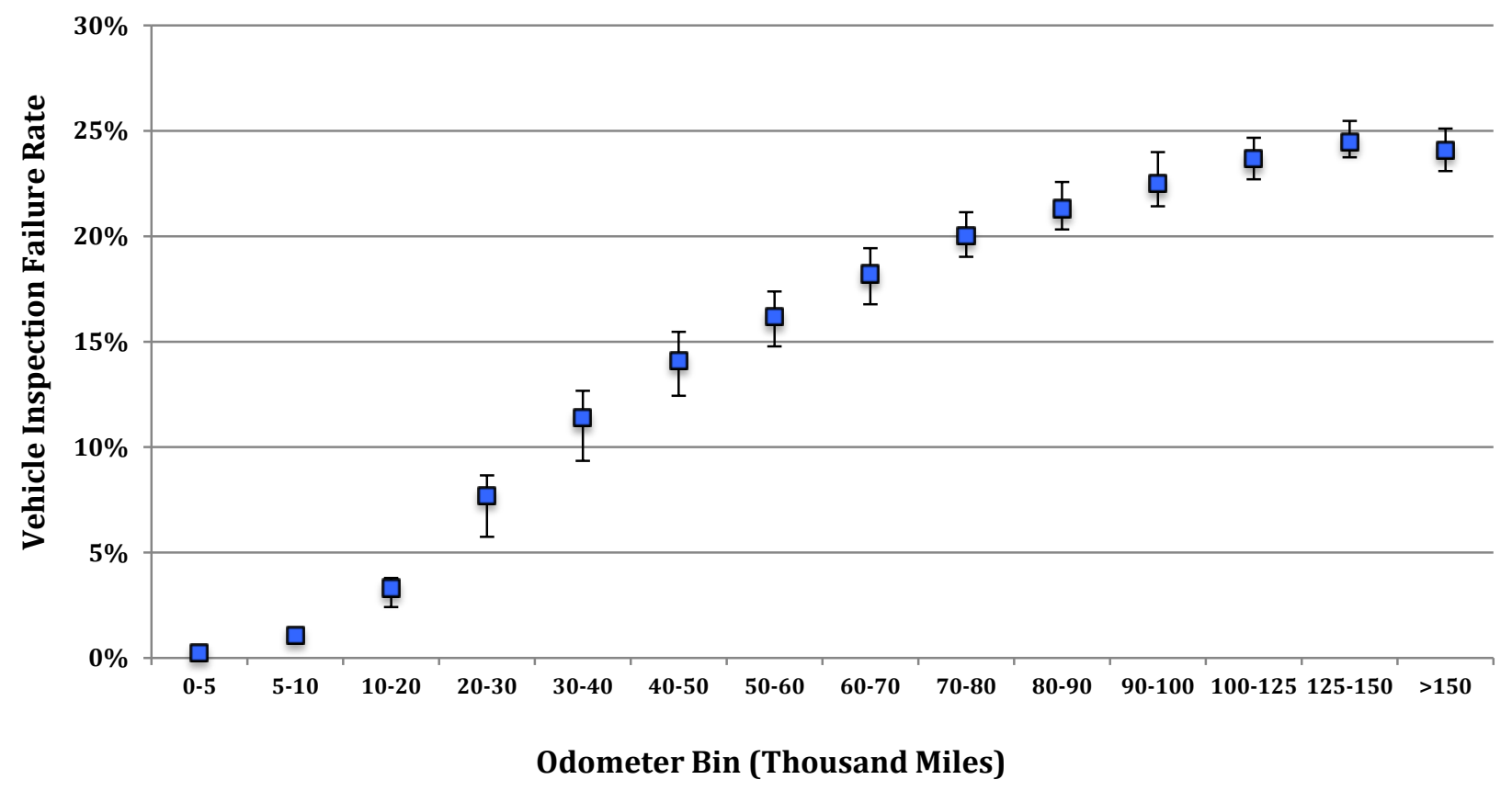

Figure 4: Average failure Rates by Vehicle Odometer Value (error bars represent min-max failure rate range from 2008-2012)

This trend suggests that there is an increased failure rate with increased odometer values. The failure rate peaks in the $125,000-150,000$ mileage bin, reflecting a failure rate of $24.5 \%$. The age and mileage characteristics are not mutually exclusive - older vehicles tend to have higher odometer readings. For example, in the combined inspection database, a three-year-old vehicle has about a 25,000 to 35,000 mile odometer reading and a ten-year-old vehicle has about a 120,000 to 130,000 mile odometer reading. For a more detailed comparison refer to the Appendix - Vehicle Miles Traveled. It is additionally noted that the failure rates are not zero for new vehicles, which are found in the two lowest odometer bins. Vehicles in odometer bins 05,000 miles and 5,000-10,000 miles have failure rates of $0.2 \%$ and $1.1 \%$, respectively and the bin for 10,000-20,000 miles driven, which equates to about a one-year-old vehicle, on average, has a failure rate of $3.3 \%$, which is above the stated $2 \%$ fleet average.

Finally, we examine failure rates by county types, which may reflect varying driving patterns and/or inspection results. The Center for Disease Control's National Center for Health Statistics (NCHS) Urban-Rural classification scheme is used to distinguish between urban and rural areas (see Figure 5). A total of six county categories were used with Type 1 denoted as 
most urban, Type 2 - Type 4 as less urban, Type 5 as rural and Type 6 as the most rural. We then used 2010 Census data [26] to assign the NCHS classification to Pennsylvania's 67 counties.

\begin{tabular}{|c|l|l|}
\hline $\begin{array}{c}\text { Category } \\
\text { code }\end{array}$ & \multicolumn{1}{|c|}{ Category name } & \multicolumn{1}{c|}{ Category description } \\
\hline Metropolitan categories & Large central metro & $\begin{array}{l}\text { NCHS-defined "central" counties of } \\
\text { MSAs of 1 million or more population }\end{array}$ \\
\hline 1 & large fringe metro & $\begin{array}{l}\text { NCHS-defined "fringe" counties of } \\
\text { MSAs of 1 million or more population }\end{array}$ \\
\hline 2 & Medium metro & $\begin{array}{l}\text { Counties within MSAs of 250,000- } \\
999,999 \text { population }\end{array}$ \\
\hline 3 & Small metro & $\begin{array}{l}\text { Counties within MSAS of 50,000 to } \\
249,999 \text { population }\end{array}$ \\
\hline Nonmetropolitan categories & $\begin{array}{l}\text { Counties in micropolitan statistical } \\
\text { areas }\end{array}$ \\
\hline 5 & Micropolitan & $\begin{array}{l}\text { Counties not within micropolitan } \\
\text { statistical areas }\end{array}$ \\
\hline 6 & Noncore
\end{tabular}

Figure 5: 2006 NCHS Urban-Rural Classification Scheme for Counties [27]

Table 5 shows the 2012 Pennsylvania county breakdown and vehicle registration representation within the urban-rural classification scheme in the state.

Table 5: 2012 Registration Data Summary of Light-Duty Passenger Vehicles by Urban-Rural County Classification

\begin{tabular}{ccccc}
\hline $\begin{array}{c}\text { County } \\
\text { Classification }\end{array}$ & \# Counties & $\begin{array}{c}\text { Total Vehicles in } \\
\text { Classification } \\
(1,000)\end{array}$ & $\begin{array}{c}\text { \% of Vehicles in } \\
\text { State }\end{array}$ & Average Age \\
\hline 1 & 2 & 1,400 & $16 \%$ & 8.7 \\
2 & 11 & 2,700 & $31 \%$ & 8.5 \\
3 & 14 & 2,700 & $31 \%$ & 9.4 \\
4 & 5 & 490 & $6 \%$ & 9.4 \\
5 & 22 & 1200 & $14 \%$ & 9.7 \\
6 & 13 & 310 & $4 \%$ & 9.7 \\
\hline
\end{tabular}

The number of counties that are designated as being rural (35) is about equal to those designated as urban (32); however, there are far more vehicles located in urban areas. While the vehicle distribution between county types is different, the inspection fail rates between the urban and rural county types are relatively consistent, ranging from $11 \%$ to $15 \%$ (see Figure 6). The calculated failure rates in each urban-rural classification are underestimates of the actual failure 
rates in the overall state and by urbanity classification. This underestimate is due to the difference in composition of vehicles in the inspection databases in comparison to the registration database, which represent a larger, overall percentage of younger vehicles with lower failure rates. Refer to the Supplemental Material (Data Representation, Supplemental Material Table 4) for a detailed disaggregation of each database by urbanity classification with averages and ranges of vehicle ages within each and further explanation of this data discrepancy.

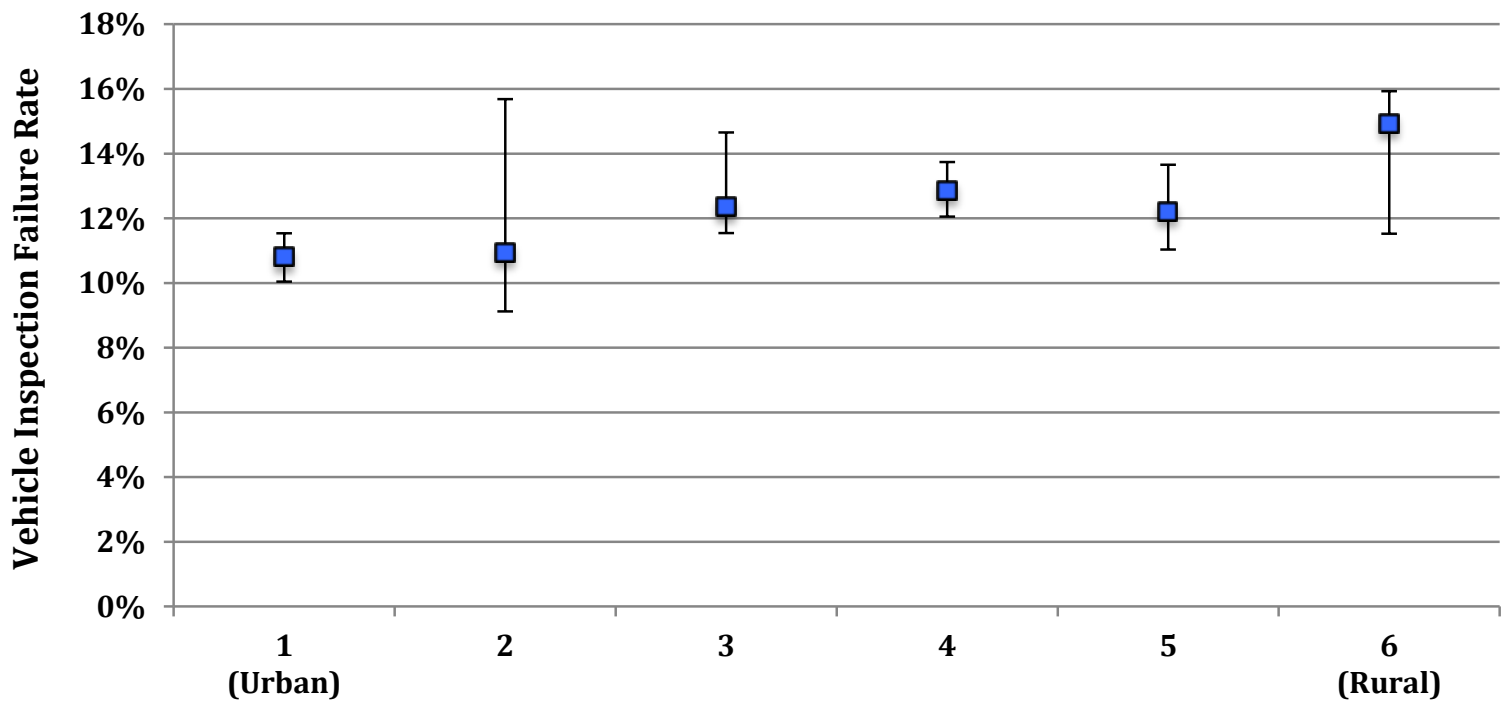

Urban - Rural County Classification

Figure 6: Average failure Rates by County Classification with error bars that represent min-max failure rate range from 2008-2012.

While these failure rate estimates are lower overall, general conclusions can still be made on the differences between urban and rural counties. The vehicle safety inspection failure rate across the state is calculated to be about $11.6 \%$, according to the metric described previously, which analyzes vehicles that need maintenance in order to pass inspection by urbanity. Using the county classification designation, the failure rate is seen to be consistent across the state, yet slightly higher in the more rural areas. Urban counties, classified as Type 1 - Type 4 according to NCHS, have a failure rate of about $11.5 \%$, similar to the calculated overall state failure rate, as these are where just over $80 \%$ of vehicles in PA are represented. The rural failure rate, counties classified as Type 5 and Type 6, was about $12.4 \%$ and represents just under $20 \%$ of the vehicle fleet in the state (Type 5 counties represent about $80 \%$ of the vehicles registered in the rural 
category and Type 6 only $20 \%$ of the rural vehicles registered). As noted previously, since the inspection database has a much higher percentage of younger vehicles than registered in the state, the urban and rural failure rates, in addition to the overall state failure rate, is likely underestimated. This conclusion is proven further by referring to the failure rate distribution by age (Figure 2) alongside the age distribution by county classification (Supplemental Material Table 4).

On a more detailed level, the difference in failure rate between the most urban and most rural county classification ranged from $11 \%$ in the most urban category to $15 \%$ in the most rural category (equating a four percentage point difference). Looking more in depth at the vehicle fleet between the most urban and most rural county classifications, a calculated one year difference in vehicle age as well as a 20,000 mile difference in odometer reading is observed (refer to Table 5). From these results, it can be concluded that on average, vehicle odometer readings and ages are higher in more rural settings than in urban settings, resulting in higher failure rates in rural categories.

Using the failure rate by age distribution along with the average vehicle age in the most urban (8.7 years) versus the most rural (9.7 years) counties that was calculated previously, it is observed that this age difference is associated with a failure rate difference of about 1.5 percentage points (refer to Figure 2). This observed rate is less than the 2 percentage point average difference between most urban and most rural counties and higher than the 1 percentage point difference when comparing the average urban (11.5\%) and average rural failure rates (12.4\%). As a result, this high rural failure rate can partially be attributed to rural counties having slightly older vehicles on average.

Using this failure rate by odometer distribution along with the average vehicle mileage in the most urban $(40,000$ miles) versus the most rural $(59,000)$ counties that was calculated previously, it is observed that this 20,000 mile odometer difference, in this odometer bin range, is associated with a failure rate difference of about 4 percentage points (see Figure 4), more than the failure rate difference calculated in the vehicle age urban-rural difference. This observed rate is equal to the four percentage point difference between the most urban and most rural counties, calculated previously, and higher than the 1 percentage point difference when comparing the average urban (11.5\%) and average rural failure rates (12.4\%). As a result, this high rural failure rate is concluded to be a result of the larger observed odometer readings in rural counties with 
even stronger evidence than seen when analyzing the differences in ages. Observing that vehicle safety inspection failure rates are consistent across counties and failure rate differences are primarily due to age and odometer differences, a safety inspection program implemented by county classification, similar to the current emission inspection program, is not ideal from a policy perspective.

Vehicle age and mileage can be used similarly in describing a vehicle and classifying appropriate inspection failure trends; however, these characteristics were shown separately in response to the recent legislature proposals to exempt vehicles by specific ages or mileages. The noticeable difference between these two distributions in Figure 2 and Figure 4 is the size of the range bars on the average estimates; they are much smaller when looking at the odometer distribution graph. This means mileage may be a better predictor of failure rates rather than age of vehicles. Additional analysis was executed in order to find the average ages of vehicles within these odometer bins (see the Supplemental Material Table 11). The findings align with the average vehicle driving about 10,000-12,000 miles per year.

\section{LONG-TERM FAILURE RATE TRENDS}

One of the initial sentiments that prompted the study was that vehicles have "never been safer" according to recent studies by the National Highway Traffic Safety Administration (NHTSA) and state legislators' beliefs that modifications to the current vehicle safety inspection program are in order. Typically this phrase that vehicles have "never been safer" corresponds to protecting users from crashes and loss of life, by improving the anti-lock brake systems or vehicle frame technology to resist crashes (or at least mitigate harmful crashes); the focus here is improved personal safety technology. In this respect, vehicle safety has improved each year (as vehicle technology also improves each year); in fact, NHTSA found that "fatal crashes decreased by 2.2 percent from 2009 to 2010, and the fatality rate dropped to 1.11 fatalities per 100 million vehicle miles of travel in 2010" compared to 1.73 fatalities per 100 million vehicle miles traveled in 1994. [28] In the case of this study, we focus specifically on observing the safety of vehicle components because, as with any item that incurs stress or wear, maintenance is necessary for proper functioning. We identify vehicle safety in terms of vehicle maintenance by analyzing failure rate trends over time. This is reflected in Figure 7, where failure rates are followed for a given model year vehicle as it ages. 


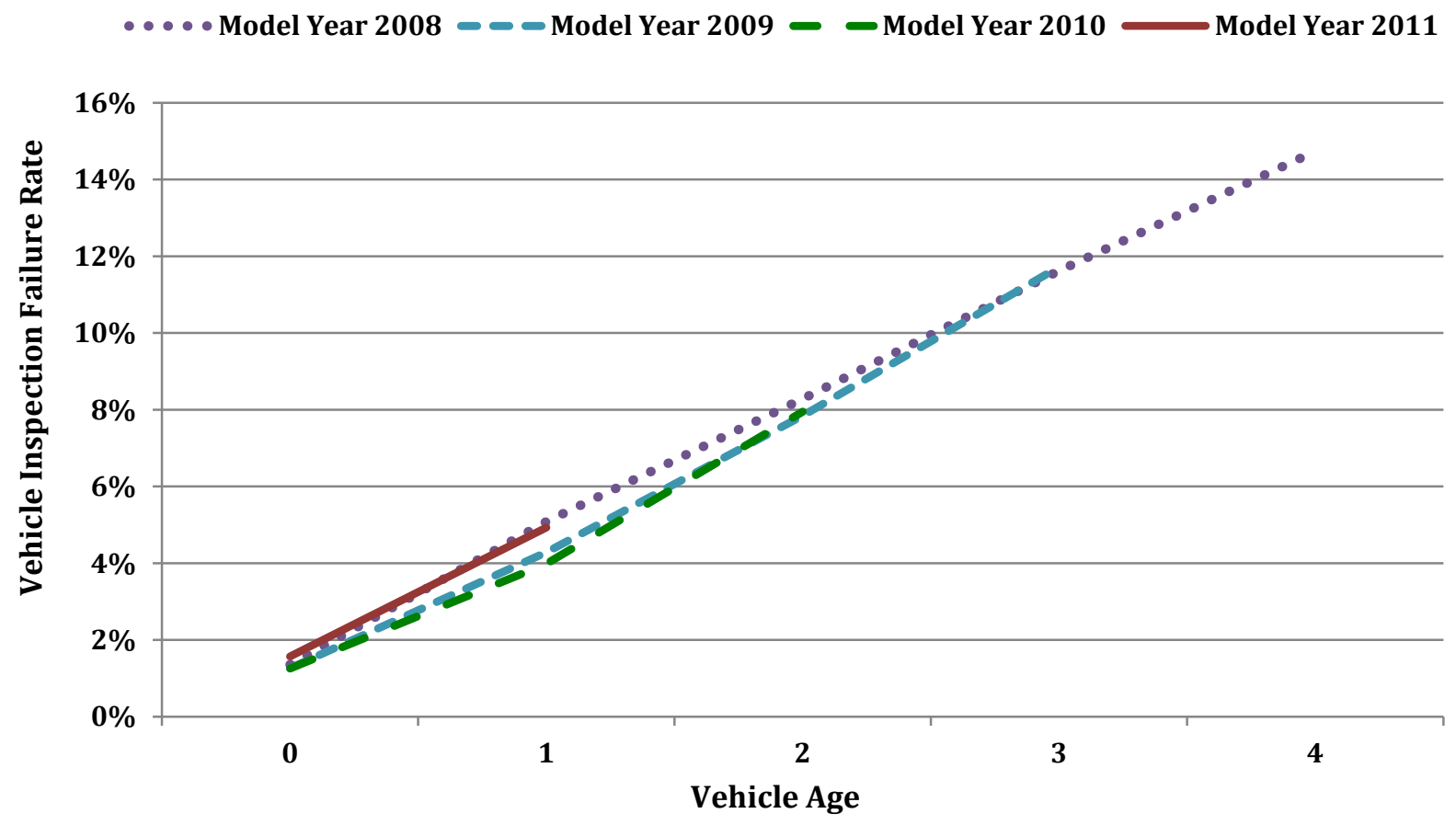

Figure 7: Time-series analysis comparing vehicle model year failure rates as the vehicle ages.

Looking at each newer model year, the same failure rate trend is still observed in an increasing trend as vehicles age. Additionally, comparing each model year by its age, a consistent failure rate is observed, resulting in the conclusion that even as technology improves, therefore improving vehicle safety ratings, failure rate trends do not appear to decrease with newer model years (Figure 7). Finally, as stated previously, brand new vehicles are not averaging a zero fail rate and any vehicle greater than one year old has a higher failure rate than the $2 \%$ failure rate referred to by policymakers.

Over four model year vehicle fleets, a consistent failure rate trend is observed as a vehicle ages. There is not enough data for model year 2011 vehicles to draw any conclusions other than that the failure rates are non-zero and mostly above the $2 \%$ promoted failure rate at age 0 and age 1, respectively. Comparing model years 2008 through 2010 from oldest to newest, a slight decrease in failure rates is observed. This is illustrated more clearly in Figure 8. 


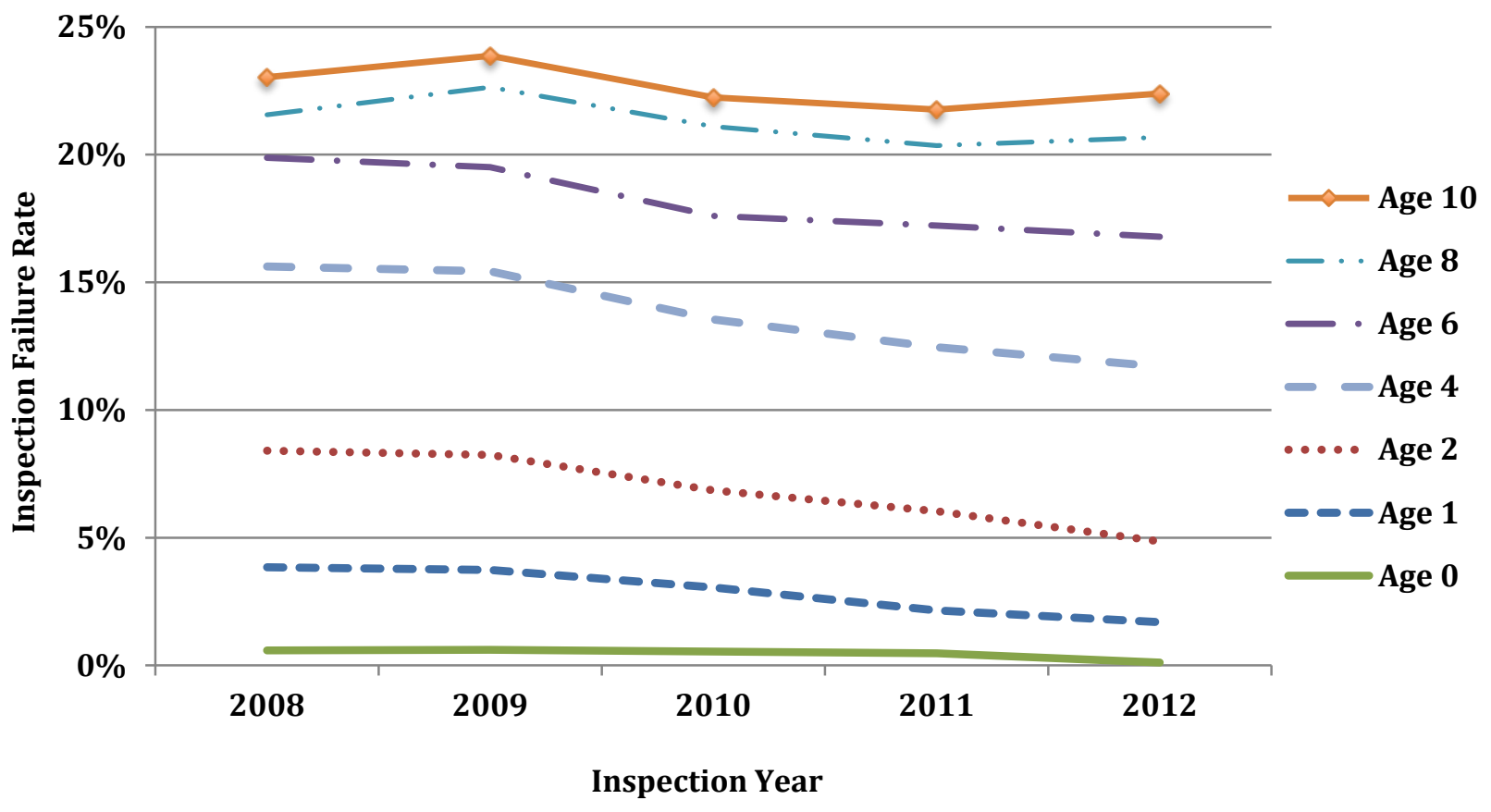

Figure 8: Inspection Failure Rate Time Series, Comparing Vehicle Age

Some vehicles generally do have higher safety ratings in newer car models; however, this must be kept isolated from the maintenance and upkeep of the vehicles. While technology has vastly improved over the past 10-20 years, and newer vehicles have higher safety ratings, yearly maintenance is still crucial to keep vehicles functioning as safe as the newest vehicles on the road; thus the importance of vehicle safety inspections.

The decreasing failure rate trend seen above in the same-aged vehicle failure rate over time, could be due to improvements in vehicle safety, but also due to factors such as the overall decrease in per capita VMT (e.g., less wear on vehicle). [29] Since people are driving less in recent years, there is less wear on the vehicle, and as a result there is a slight decrease in the observed failure rates.

\section{CONCLUSIONS}

State policymakers periodically question the effectiveness of the passenger vehicle safety inspection programs. By considering how the inspection process works and analyzing the state of the vehicle upon entering the inspection rather than leaving, a more comprehensive examination of the current inspection program and its effectiveness can be provided. These compelling 
findings put into question why safety inspections are not federally mandated along with emission inspections, as safety inspection failure rates remain high.

The average initial vehicle inspection failure rate range between all databases is about $12 \%$ to $18 \%$, at least an order of magnitude higher than the assumed rate of $2 \%$. After inspection and repairs, the failure rate of vehicles with fail as the final inspection status is much lower, with only $0.1 \%$ of vehicles ultimately failing. Additionally, this estimated $12 \%$ to $18 \%$ rate, combined with the Pennsylvania vehicle fleet size of about 10.4 million, equates to on the order of 1.2 to 1.9 million vehicles that would have failed the safety inspection in a given year - the number of vehicles that would have failed without the current program. Furthermore, when analyzing the data in more detail, many groups of vehicles are well above this average fail rate, especially vehicles more than three years old or with more than about 30,000 cumulative miles. Vehicles less than one year of age still do not average a zero failure rate and most one-year-old vehicles are at or above the believed $2 \%$ failure rate. Policy makers must use this information as the basis for policy change, rather than the pass or fail rate with the current inspection program in place (i.e., as a vehicle leaves the inspection station).

While estimates of the safety inspection program's effect on highway crashes or fatalities in Pennsylvania are outside the scope of this paper, Cambridge Systematics, Inc. (2009), previously summarized in the literature review of this paper, estimated 1 to 2 fewer safety related fatalities per billion VMT in a state with versus without a safety inspection program. Based on this paper's model results, they find Pennsylvania benefits from between 127 and 187 fewer fatalities each year, as a result of the vehicle safety inspection program. Applying the value of a statistical life to these fatality avoidances, this benefit of lives saved is then compared to user costs of the inspection program. The authors of the Cambridge paper conclude that in every case, the benefits outweigh the calculated program costs by at least $\$ 100 \mathrm{M}$, making the program worthwhile to continue to implement. Future work should include an in depth analysis of current inspection program costs, including costs to both the user and the state, versus the program's benefits in reducing fatalities.

Broader collection of accurate inspection data is needed as well as a more randomly selected fleet of vehicles. If electronic inspection databases were the norm, real-time data analysis would be invaluable in showing the most realistic failure rates. While the e-SAFETY and CompuSpections databases provide varying samples of the population, they are the only 
databases available with this information. Both are similar in information that is collected; however, the CompuSpections database seemed to have a larger sample size and more accurate information (e.g., fewer data entries needed to be filtered out). Eventually, fully electronic record collection would be ideal in order to monitor failure rates of specific stations and even specific inspectors, so as to eliminate any incorrect assessments as they happen or soon after.

A larger and more comprehensive data collection system is key to a more effective inspection program and will allow for stronger oversight and improved management. Initially the vehicle safety inspection program was periodically audited by state police officers two times per year per station. These audits have decreased significantly and now vary between attainment and non-attainment emission counties. The paper-based inspection program requires significant program oversight, traveling, and training. A system similar to the CompuSpections and eSAFETY programs, with electronic data collection as well as error checking, would provide more efficient recording of data, as well as data analysis in order to provide on-demand reports of how the program is performing. This study is limited to the available data. Currently, there are few states with vehicle safety inspection programs and even fewer with electronic safety inspection records. Without this information, these results are limited to the state of Pennsylvania. Data from other states would allow this study to be extrapolated to the national level and in return, this would validate the results in Pennsylvania. 


\section{ACKNOWLEDGEMENTS}

This material is based upon work supported by the National Science Foundation under Grant No. 0946825. Additional support came from a US DOT University Transportation Center Grant (award No. DTRT12GUTC11) and from the Pennsylvania Department of Community and Economic Development's Pennsylvania Infrastructure Technology Alliance (PITA). The Pennsylvania Department of Transportation provided anonymized vehicle inspection data and anonymized vehicle registration data. CompuSpections, Inc. provided an additional anonymized vehicle safety inspection database. The views in this paper are those of the authors and not of the National Science Foundation, the Department of Transportation, or the Pennsylvania Department of Community and Economic Development. 


\section{REFERENCES}

[1] R. I. T. Administration, Ed., National Transportation Statistics. [Online]. Available: http://www.rita.dot.gov/bts/sites/rita.dot.gov.bts/files/publications/national_transportatio n_statistics/html/table_01_40.html. [Accessed: 13-Feb-2014].

[2] Digest of Motor Laws. [Online]. Available: http://drivinglaws.aaa.com/laws/safetyinspection/\#. [Accessed: Mar-2014].

[3] T. Barnes, "Pennsylvania measure would end inspections for new vehicles," PostGazette, 15-Oct-2012.

[4] T. Craig, Ed., D.C. Ending Required Safety Inspections on Private Cars, 2009. [Online]. Available: http://www.washingtonpost.com/wpdyn/content/article/2009/09/14/AR2009091402794.html. [Accessed: Jul-2014].

[5] M. Frassinelli, Ed., N.J. will drop requirements for mechanical inspections of cars to save \$11M yearly, 2010. [Online]. Available:

http://www.nj.com/news/index.ssf/2010/07/nj_to_drop_requirements_mechan.html. [Accessed: Jul-2014].

[6] U. S. D. O. Transportation, Ed., Highway Safety Improvement Program History. [Online]. Available: http://safety.fhwa.dot.gov/hsip/gen_info/hsip_history.cfm. [Accessed: 03-Jan-2014].

[7] P. Bonsall, R. Liu, and W. Young, "Modelling safety-related driving behaviour-impact of parameter values," Transportation Research Part A: Policy and Practice, vol. 39, no. 5, pp. 425-444, Jun. 2005.

[8] R. B. Noland and M. A. Quddus, "Congestion and safety: A spatial analysis of London," Transportation Research Part A: Policy and Practice, vol. 39, no. 7, pp. 737-754, Aug. 2005.

[9] M. Abdel-Aty, J. Lee, C. Siddiqui, and K. Choi, "Geographic unit based analysis in the context of transportation safety planning," Transportation Research Part A, vol. 49, no. C, pp. 62-75, Mar. 2013.

[10] W. Weijermars and P. Wesemann, "Road safety forecasting and ex-ante evaluation of policy in the Netherlands," Transportation Research Part A, vol. 52, no. C, pp. 64-72, Jun. 2013.

[11] W. M. Crain, "Vehicle safety inspection systems: How effective?," American Enterprise Institute, Washington, D.C., P-25 Series, 1980.

[12] P. D. Loeb and B. Gilad, "The Efficacy and Cost-Effectiveness of Vehicle Inspection," Journal of Transport Economics and Policy, vol. 18, no. 2, pp. 145-164, May 1984.

[13] P. D. Loeb, "The Efficacy and Cost Effectiveness of Motor Vehicle Inspection Using Cross-Sectional Data," Southern Economic Journal, vol. 52, no. 2, pp. 500-509, Oct. 1985.

[14] C. Garbacz and G. Kelly, "Automobile Safety Inspection: New Econometric and benefit/cost estimates,” Applied Economics, vol. 19, no. 6, pp. 763-771, 1987.

[15] J. P. Leigh, "Nonrandom Assignment vehicle safety inspection laws and highway fatalities," Public Choice, no. 78, pp. 373-387, 1994.

[16] D. Merrell, M. Poitras, and D. Sutter, "The Effectiveness of Vehicle Safety Inspections: An Analysis Using Panel Data," Southern Economic Journal, vol. 65, no. 3, pp. 571583, Jan. 1999.

[17] M. Poitras and D. Sutter, "Policy Ineffectiveness or Offsetting Behavior?," Southern 
Economic Journal, vol. 68, no. 4, pp. 922-934, Apr. 2002.

[18] D. Sutter and M. Poitras, "The Political Economy of Automobile Safety Inspections Springer," Public Choice, vol. 113, no. 3, pp. 367-387, 2002.

[19] C. McCahill, "Per capita VMT drops for ninth straight year; DOTs taking notice," State Smart Transportation Initiative, Feb. 2014.

[20] Cambridge Systematics Inc., "Pennsylvania's Vehicle Safety Inspection Program Effectiveness Study," pp. 1-79, Mar. 2009.

[21] Doubtful Return on the Public's \$141 Million Investment in Poorly Managed Vehicle Inspection Programs. [Online]. Available:

http://www.ncleg.net/PED/Reports/documents/VSI/VSI_Report.pdf. [Accessed: 03-Mar2014].

[22] The Pennsylvania Code, Fry Communications, Inc., Jan. 2014.

[23] P. D. O. Transportation, "Pennsylvania's e-SAFETY Program Publication," vol. 1, no. 1, pp. 1-4, Oct. 2007.

[24] O. R. N. Laboratory, "Transportation Energy Databook,” Jul. 2013.

[25] S. Menard, Applied Logistic Regression Analysis, 2nd ed. Sage Publications, Inc., 2001.

[26] U. S. C. Bureau, Ed., Population Estimates. [Online]. Available: http://www.census.gov/popest/data/index.html. [Accessed: 06-Mar-2014].

[27] Center for Disease Control, Ed., Urban-Rural Classification. [Online]. Available: http://www.cdc.gov/nchs/data/oae/NCHSUrbruralFileDocumentation.pdf. [Accessed: 03-Jan-2014].

[28] Fatality Analysis Reporting System Encyclopedia. [Online]. Available: http://wwwfars.nhtsa.dot.gov/Main/index.aspx. [Accessed: 21-Apr-2014].

[29] B. O. T. Statistics, Ed., U.S. Light-Duty Fuel Consumption and Vehicle Miles Traveled. [Online]. Available: http://www.afdc.energy.gov/data/search?q=U.S.+LightDuty+Fuel+Consumption+and+Vehicle+Miles+Traveled. [Accessed: 06-Mar-2014].

[30] GM VIN Check Digit Verification. [Online]. Available: http://people.virginia.edu/ sns5r/resint/empiostf/checkdigit.htm. [Accessed: 03-Jan2014].

[31] ALLDATA LLC., Ed., VIN to Year Chart. [Online]. Available: http://support.alldata.com/alldata-repair-online-article/vin-to-year-chart. [Accessed: 03Jan-2014].

[32] National Highway Traffic Safety Administration and P. D. O. Transportation, Vehicle Identification Number Requirements: Final Rule. 2008, pp. 1-77. 